\title{
Over-expression of AQUA1 in Populus alba Villafranca clone increases relative growth rate and water use efficiency, under $\mathrm{Zn}$ excess condition
}

\author{
Andrea Ariani ${ }^{1,2} \cdot$ Alessandra Francini ${ }^{1} \cdot$ Andrea Andreucci $^{3} \cdot$ Luca Sebastiani $^{1}$
}

\begin{abstract}
Key message Transgenic Populus alba over-expressing a TIP aquaporin (aqual) showed a higher growth rate under $\mathrm{Zn}$ excess, suggesting that aqual could be involved in water homeostasis, rather than in $\mathrm{Zn}$ homeostasis. Abstract Populus is the internationally accepted model for physiological and developmental studies of tree traits under stress. In plants, aquaporins facilitate and regulate the diffusion of water, however, few poplar aquaporins have been characterized to date. In this study, we reported for the first time an in vivo characterization of Populus alba clone Villafranca transgenic plants over-expressing a TIP aquaporin (aqual) of $P$. $x$ euramericana clone I-214. An AQUA1:GFP chimeric construct, over-expressed in $P$. alba Villafranca clones, shows a cytoplasmic localization in roots, and it localizes in guard cells in leaves. When over-expressed in transgenic plants, aqual confers a higher growth rate compared to wild-type (wt) plants, without affecting chlorophyll accumulation, relative water content (RWC), and fluorescence performances, but increasing the intrinsic Transpiration Efficiency. In response to $\mathrm{Zn}$ ( $1 \mathrm{mM}$ ), transgenic lines did not show a significant increase in $\mathrm{Zn}$ accumulation as compared to wt plants, even though the overexpression of this gene confers higher tolerance in root tissues. These results suggest that, in poplar plants, this gene could be principally involved in regulation of water homeostasis and biomass production, rather than in $\mathrm{Zn}$ homeostasis.
\end{abstract}

Keywords Aquaporin · Villafranca clone - Growth ·Photosynthesis · Zinc 
Water is the medium of life, and almost every living organisms need this molecule for accomplishing its basics physiological functions. Before the discovery of the first water channel protein in red blood human cells (Agree et al. 1987), it was thought that water, being a small polar molecule, crosses biological membrane only through pas- sive diffusion across cellular lipid bilayer (Maurel 1997). After the discovery of the first human aquaporin, novel perspectives were Introduction

opened to the study of plant-water relationships. Aquaporins facilitate and regulate the diffu- sion of water and other small molecules (e.g., urea, ammonium and glycerol) across biological membranes and are involved in almost all plant physiological processes such as growth, development, and response to biotic and abiotic stresses (Li et al. 2013). Aquaporins belong to the major intrinsic protein superfamily (MIP), and in plants form a large gene family with more than thirty members identified in each genome of Arabidopsis, Zea mays, Oryza sativa, Populus trichocarpa and Phaseolus vulgaris (Quigley et al. 2001; Chaumont et al. 2001; Sakurai et al. 2005; Gupt and Sankararamakrishnan 2009; Ariani and Gepts 2015). In higher plants, these proteins can be divided into 5 sub-families, according to sequence similarity and sub-cellular localization: the Plasma membrane Intrinsic Proteins (PIPs), Tonoplast Intrinsic Proteins (TIPs), Nodulin26-like Intrinsic Proteins (NIPs), Small basic Intrinsic Proteins (SIPs), and unrecognized X Intrinsic Proteins (XIPs) (Li et al. 2013).

Populus spp. is the internationally accepted model for physiological and developmental studies on tree-specific traits, that are not possible in herbaceous plants (Tuskan et al. 2006; Wullschleger et al. 2012). Due to the high biomass production, fast growth rate, and transpiration of this species, aquaporins are probably central in the regulation of water flow and in the developmental processes of these plants. In addition, across sequenced plants, Populus trichocarpa has the highest number of MIP genes identified in its genome sequence to date (Gupt and Sankararamakrishnan 2009) probably as a consequence of the Sali- coid genome duplication (Rodgers-Melnick et al. 2012). Despite the high number of aquaporin genes in the Populus genome, their physiological roles have been only partially elucidated in this species, mainly through expression analysis. In particular, in different Populus genotypes aquaporins are differentially expressed during root devel- opment, mycorrhizal symbiosis, and in recovery to xylem embolism (Kohler et al. 2003; Marjanovic et al. 2005; Secchi and Zwieniecki 2010). Furthermore, some aqua- porin genes were found to be responsive to abiotic stresses and hormone treatments (Bae et al. 2011; Hacke et al. 2010; Lopez et al. 2012). A more comprehensive survey of aquaporin expression profiles of several Populus microar- ray experiments highlighted a high degree of functional divergence across duplicated genes of this family, sug- gesting then specific regulation of single aquaporin genes in response to environmental cues (Cohen et al. 2013).

Even though gene expression analysis could give valu- able information on aquaporin function in plant physiology (Sakurai et al. 2005; Besse et al. 2011), Agrobacterium- mediated transformation seems to be a better approach for this kind of study, allowing in vivo functional characteri- zation of single gene products and analysis of their role at whole plant level. This technology has been widely exploited for studying aquaporin genes in several herba- ceous plant species such as Arabidopsis thaliana (Cui et al. 2008; Postaire et al. 2010; Lee et al. 2012), Oryza sativa (Li et al. 2008; Matsumoto et al. 2009), Solanum lycop- ersicum (Sade et al. 2009), and Vitis vinifera (Perrone et al. 2012). These studies have allowed a better characterization of the roles of single aquaporin genes in plant-water relations, biomass production, and stress responses. Inter- estingly, studies on stress responses in transgenic plants over-expressing an aquaporin of interest highlighted opposite effect for different aquaporins, that could confer either higher tolerance or sensitivity (Li et al. 2013). Thanks to the availability of several protocols for Agrobacterium-mediated transformation of different Populus clones (Song et al. 2006), several reverse engineering approaches have been applied for studying different Pop- ulus genes such as transcription factors involved in sec- ondary growth differentiation (Robinschon et al. 2011; Du et al. 2011) and stress responses (Su et al. 2011). However, few studies using Agrobacterium-mediated transformation of endogenous aquaporins have been performed in this species to date.

In this study, we report an analysis of $P$. alba (Vil- lafranca clone) transgenic lines over-expressing an aquaporin (GenBank: GQ918138) of $P$. x euramericana I-214 clone in different expression vectors. Transgenic lines carrying an AQUA1:GFP construct under the $35 \mathrm{~S}$ promoter have been created for analyzing the sub-cellular localization of this aquaporin in different organs and tissues. Additionally, AQUA1:HA over-expressing lines have been characterized for growth and photosynthetic parameters, in comparison to wild-type (wt) plants, in order to understand the physiological role of this protein in Populus.

Response to excess $\mathrm{Zn}$ is a complex phenomenon in poplar trees, entailing variation in biochemical and physiological processes, but also anatomical adaptation to toxic concentration of this metal (Di Baccio et al. 2009, 2011). These differences were related also to organ-specific vari- ation in transcriptome and proteome, with activation of ROS detoxifying mechanisms, regulation of heavy metal transporters, and Nitrogen and Carbon metabolisms in response to excess Zn (Di Baccio et al. 2011; Romeo et al. 2014a; Ariani et al. 2015). Physiological analysis of 
response to excess $\mathrm{Zn}$ in different poplar clones showed also a genotype specific response toward this metal, with variation in sensitivity, metal concentration, and allocation among different poplar clones (Romeo et al. 2014b). However, a common response was the concentration of the majority of $\mathrm{Zn}$ in roots tissues, probably for protecting photosynthetic tissues.

Previous studies on aqual showed its down-regulation in both leaves and roots in response to excess $\mathrm{Zn}$ in I-214 hybrid poplar clone, regulation of sub-cellular localization by post-translational modifications in response to this heavy metal in Arabidopsis protoplast, and also a protec- tive role of this gene in yeast $\mathrm{Zn}$-hypersensitive strains (Di Baccio et al. 2011; Andreucci et al. 2015). Several studies highlighted the ability of some aquaporins to transport metals and to confer heavy metal resistance when over- expressed in transgenic plants (Zhang et al. 2008; Hove and Bhave 2011; Negishi et al. 2012). In addition, $P$. alba (Villafranca clone) has been reported as a promising poplar clone for possible phytoremediation applications (Romeo et al. 2014b).

This experiment was set up in order to test the hypoth- esis that aqual transgenic lines have different $\mathrm{Zn}$ tolerance in comparison to the wt.

\section{Material and method}

\section{Plant transformation and in vitro propagation}

The codifying sequence of aqual was excised from pYES vector with XbaI and BamHI restriction enzymes. The XbaI end was filled in for having a blunt-end of the excised aqual coding fragment. The pENTR 1A entry vector was digested with BamHI and EcoRV restriction enzymes and the aqual coding fragment was ligated inside this vector. The aqual full coding DNA sequence (CDS) inside pENTR 1A vector was then cloned in different expression vectors using Gateway (LifeTechnology) recombination technology according to manufacturer's instruction (Zhang et al. 2006; Nakagawa et al. 2008). Two different expres- sion vectors were used for the different purpose of this study. The first vector was the pMDC45 that determines the expression of AQUA1:GFP chimeric construct under the 35S promoter and was used for subsequent sub-cellular and organs localization of AQUA1:GFP protein in transgenic plants. The second vector, in which aqual sequence was cloned, was the pEarlyGate-201 that carried the full CDS sequence of aqual in frame with the hemoagglutinin (HA) tag. Plants transformed with this vector were used for subsequent phenotypic characterization of AQUA1 over- expressing transgenic poplars, since the HA-tag should not disturb aqual functions and folding.

Both vectors were transformed in the Agrobaterium LB4404 strain (LifeTechnology) with the Gene Pulser X-cell electroporation system (Biorad, Berkeley, CA, USA) according to manufacturer's protocol, and in vitro plantlets of Populus alba Villafranca L. clone were trans- formed with this Agrobacterium strain as described in Confalonieri et al. (2000). After regeneration, transfor- mants were selected in selective media with $10 \mathrm{mg} / \mathrm{L}$ hygromicin or $5 \mathrm{mg} / \mathrm{L}$ BASTA, depending on the trans- formation vectors utilized. Plants, able to root in these media (i.e., resistant to the selection), were considered transgenic and further propagated and multiplied in WPM medium as separated lines.

\section{Expression analysis}

Expression analyses of 10 separate transgenic lines (data not shown) were performed first on in vitro whole plantlets using three technical replicates for each line following the same methodology reported below for in vivo plants. Then, two transgenic lines were selected for acclimation and in vivo analysis. After, we will refer to the two transgenic lines as line 16 and line 22. For in vivo experiments of aqual:HA over-expressing lines, the maintenance of the transgene was tested by performing the last in vitro mul- tiplication step (before acclimation) on selective media. In addition, the in vitro culture of a group of wt Populus alba

L. Villafranca clone was synchronized with transgenic lines during propagation and multiplication steps and all the plants for in vivo analysis were acclimated together. In vivo expression was then analyzed on leaves of two acclimated transgenic lines (line 16 and 22), performing three technical replicates for three independent biological samples.

The relative expression of aqual transcript in AQUA1:HA transgenic lines was compared with the endogenous gene of $P$. alba Villafranca clone. Total mRNA was extracted using $80-100 \mathrm{mg}$ of frozen $\left(-80^{\circ} \mathrm{C}\right)$ leaves, with the RNeasy plant mini kit (Qiagen) according to the manufacturer's protocol. Total RNA was treated with RNase-free DNase (Qiagen) in order to remove genomic DNA contamination prior to quantification and reverse transcription. RNA quality and concentration were evalu- ated with the Experion RNA StdSens Kit (Biorad), and 1 lg of total RNA was reverse transcribed with Quantitect Reverse Transcription Kit (Qiagen) according to the man- 
ufacturer's protocol. Real-time PCR analyses were per- formed using the Quantitect SYBR Green PCR Kit (Qiagen) according to manufacturer's protocol on ECO Real-Time PCR System (Illumina Inc. San Diego, USA).

As a reference gene, the primers from Brunner et al. (2004) were tested and alfa-tubulin (forward $5^{0}$ AGGTTC TGGTTTGGGGTCTT3 ${ }^{0}$, reverse $5^{0}$ TGTCACGTCTGTG

TGCTCAA $3^{\circ}$ ) was selected as for more suitable reference gene for our experimental condition, allowing the gene normalization and quantification. For Real-Time PCR experiments on aqual gene, the following primers were used: forward $5^{\circ} \mathrm{CCTCCGTGGCATTCTGTATT3}{ }^{\circ}$, reverse $5^{\circ} \mathrm{CAAAGGTCCAGCCCAGTAAA} 3^{\circ}$.

\section{Confocal imaging}

The fluorescence of in vitro transgenic plants overex- pressing the AQUA1-GFP construct were visualized by confocal laser scanning microscopy. Leaves and roots of transgenic plants were analyzed with an inverted Leica TCS SP2 confocal laser scanning microscope (Leica Microsystems, http://www.leica.com), using a 63X NA 1.3 Plan-Apo oil-immersion objective at 102491024 pixel resolution. For GFP fluorescence analyses, we used the 488 $\mathrm{nm}$ excitation line of an argon ion laser and the emission light was dispersed and recorded at 500-535 nm.

\section{Plant growth and $\mathrm{Zn}$ treatment}

Plantlets of Populus alba L. Villafranca clone derived from in vitro culture were acclimatized in vivo for 3 weeks in a growth chamber under controlled environmental conditions $\left(23: 18{ }^{\circ} \mathrm{C}\right.$ day:night temperature, $65-70 \%$ relative humidity, and $16 \mathrm{~h}$ photoperiod at photosynthetic photon flux density of $4001 \mathrm{~mol} \mathrm{~m}^{-2} \mathrm{~s}^{-1}$ supplied by fluorescent lights). Plantlets from in vitro culture were transferred from Magenta vessels with WPM half-strength solid medium (Lloyd and McCown 1981) to pots filled with perlite (Laterlite, Milano Italy), closed in plexiglass boxes in order to maintain the high humidity (100\%) typical of in vitro cultures. During the acclimation process, the nutrient sup- ply was gradually changed from WPM half-strength liquid medium to Hoagland's solution (Arnon and Hoagland 1940) and relative humidity was reduced from $100 \%$ to $65-70 \%$ (growth chamber parameter) in order to adapt plants to the in vivo conditions. After the acclimation period, the plants were transferred into plastic pots, con- taining 8-20 $\varnothing \mathrm{mm}$ expanded Agrileca clay (Laterlite, Milano Italy) and grown hydroponically on a basic Hoag- land's nutrient solution at pH 6.2 as described by Arnon and Hoagland (1940), renewed every week and continu- ously aerated by aquarium pumps $\left(250 \mathrm{l} \mathrm{h}^{-1}\right)$. After 4 weeks of acclimation to hydroponic conditions, five (5) plants were destructively sampled in order to determine the initial fresh (FW) and dry weight (DW) of roots, stem, and leaves. The remaining plants (10 for each transgenic line and 10 for wt) were randomly divided in two groups $(n=5)$ and assigned to two different $\mathrm{Zn}$ treatments for 5 weeks (35 days): $1 \mathrm{lM} \mathrm{Zn}$ as control and $1 \mathrm{mM} \mathrm{Zn}$ as treatment. According to previous knowledge (Ariani et al. 2015; Di Baccio et al. 2011), $1 \mathrm{mM}$ was the $\mathrm{Zn}$ concen- tration in which aqual was down-regulated in P. x euramerica I-214 clone in both roots and leaves (Di Baccio et al. 2011). In addition, this concentration has also been shown to increase $\mathrm{Zn}$ accumulation in Populus alba $\mathrm{L}$. Villafranca clone in hydroponic condition (Romeo et al. 2014b). $\mathrm{Zn}$ was supplied as zinc nitrate hexahydrate $\left(\mathrm{Zn}\left(\mathrm{NO}_{3}\right) 2 \cdot 6 \mathrm{H}_{2} \mathrm{O}\right)$, and iron as Fe-tartrate instead of Fe- EDTA for avoiding possible $\mathrm{Zn}$ chelation by EDTA.

Leaf weight ratio (LWR), stem weight ratio (SWR), and root weight ratio (RWR) were calculated as the fraction of the total biomass allocated to the leaves, stem, and root [organ mass (g)/mass of plant (g)] to whole plants (Hunt 1978).

\section{Growth and Zn content analysis}

At the end of the experiment $\left(T_{1}=35\right.$ days), each plant was harvested, rinsed with deionized water, and separated into leaf, stem, and root. Disks $(1 \varnothing \mathrm{cm})$ from fully expanded leaves, with leaf plastochron index (LPI) equal to 5, were collected in pre-weighed Petri dishes. The Petri were sealed immediately and weighed to obtain the fresh weight (FW). Leaf samples were placed in distilled water and kept at $4{ }^{\circ} \mathrm{C}$ overnight. The samples were then weighed (saturated weight, SW) and then dried at $60{ }^{\circ} \mathrm{C}$ for 2 days and weighed (dry weight, DW). RWC was calculated from the equation: RWC \%1/41/2ðFW -DWP=ðSW -DWP] X 100. DW of each sampled plant parts harvested was deter- mined after drying at $60{ }^{\circ} \mathrm{C}$ until their weight remained constant. Relative growth rate (RGR) was determined as the differences between the natural logarithm of DW at $\mathrm{T}_{1}$ and the natural logarithm of the mean DW at $T_{0}$, divided for the day of treatment (35 days) for different plant parts or for the whole plants. Tolerance indices were calculated as described by Wilkins (1957) using the ratio between the DW biomass of treatment and control conditions. The mineral concentration inside leaves, stems, and roots was detected by Kjeldahl (1883) method (N); atomic absorption (Zn); ICP analysis (Ca, Mg, P, K, Na, S, B, Fe, Mn, Cu). The acid 
mineralization was done on $0.5 \mathrm{~g}$ dry homoge- neous samples. Samples were digested for $10 \mathrm{~min}$ into a microwavedigesting machine with a solution composed of $6 \mathrm{ml} \mathrm{HNO}_{3} 65 \%$ and $1 \mathrm{ml} \mathrm{H}_{2} \mathrm{O}_{2} 33 \%$. The resulting solutions were filtered and diluted with ultra-pure water to a $25 \mathrm{ml}$ volume and then analyzed with atomic absorption or ICP analysis.

\section{Chlorophyll, fluorescence, and gas exchange measurements}

Changes in chlorophyll concentration during the leaf mat- uration process was measured using SPAD meter (SPAD502 Plus Chlorophyll Meter, Spectrum, Plainfield, IL,USA) on three consecutive fully expanded leaves randomly selected on each plant.

Chlorophyll $a$ fluorescence transients were determined on dark-adapted leaves (30 min), using a portable Handy PEA (Hansatech, UK). The measurements were taken on the leaf surface (4 mm diameter) exposed to an excitation light intensity (ultrabright red LEDs with a peak at $650 \mathrm{~nm})$ of $30001 \mathrm{~mol} \mathrm{~m}^{-2} \mathrm{~s}^{-1}\left(600 \mathrm{~W} \mathrm{~m}^{-2}\right)$ emitted by three diodes. Leaf fluorescence detection was measured by fast-response PIN photodiode with RG9 long-pass filter (Hansatech, technical manual).

Instantaneous gas exchange and photosynthetic $\mathrm{CO}_{2}$ response curves $(\mathrm{A} / \mathrm{Ci})$ were measured on the fully expanded leaf LPI $=5$ of three plants for each $\mathrm{Zn}$ treatment and lines. All the measurements were conducted on plants at the end of the $\mathrm{Zn}$ treatments with a portable photosynthesis system (CIRAS-1 PP Systems, Hearts, UK) equipped with a Parkinson leaf chamber in saturating light between 1000 and $1200 \mathrm{~h}$ at an air tem- perature of $26-30{ }^{\circ} \mathrm{C}$. Photosynthetic rate $(\mathrm{A})$, stomatal conductance $\left(g_{\mathrm{s}}\right)$, and intercellular $(\mathrm{Ci}) \mathrm{CO}_{2}$ were mea- sured. Leaf chamber temperature and humidity were adjusted to maintain a leaf to air vapor pressure difference of $1.1 \mathrm{kPa}$. The $\mathrm{CO}_{2}$ response curves were obtained by changing the $\left[\mathrm{CO}_{2}\right]$ entering the cuvette from 50 to $1500 \mathrm{lmol} \mathrm{mol}^{-1}$ with an external $\mathrm{CO}_{2}$ cartridge mounted on the CIRAS console and automatically controlled by a $\mathrm{CO}_{2}$ injector. Gas exchange was determined at each step after exposure of the leaf to the new $\left[\mathrm{CO}_{2}\right]$ for $120-240 \mathrm{~s}$; Q was maintained at 1500 $1 \mathrm{~mol} \mathrm{~m} \mathrm{~m}^{-2}$.

\section{Statistical analysis}

The experiment was set up in a completely randomized block design with five replicate plants $(n=5)$ for each treatment.

The $t$ test analyses was performed on data $(n=3)$ about in vivo relative expression of aqual transcripts in leaves of transgenic plants $v s$ wt plants. Data $(n=5)$ of LMR, SWR, RWR, SPAD, RWC, RGR calculated on different lines after 35 days of $1 \mathrm{lM}$ and $1 \mathrm{mM} \mathrm{Zn}$ treatment, $\mathrm{Zn}$ con- centration in leaves, stems, and roots, $\mathrm{CO}_{2}$ assimilation at saturating light level, stomatal conductance to water vapor, and the intrinsic Transpiration Efficiency were subjected to a two-way ANOVA for statistical evaluation of the effects produced by $\mathrm{Zn}$, line and interaction of these two factors. Means were subjected to Tukey's Multiple Comparison Test at 0.05 probability level.

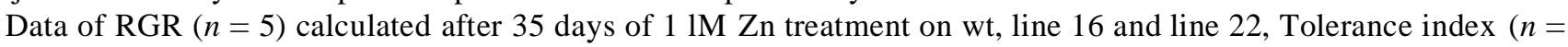
5) and aqual relative expression $(n=3)$ in vivo leaves were subjected to one-way ANOVA and Tukey's Multiple Comparison Test $(P \backslash 0.05)$. ANOVA was per- formed using NCSS 2000 Statistical Analysis System Software.

A principal component analysis (PCA) was performed to help the identification of the element distributions in plants in relation to $\mathrm{Zn}$ uptake. PCA is designed to reduce a dataset containing a large number of variables to a smaller size by finding a new set of variables called components, each being a linear combination of the original variables. The number of derived components is the same as the number of original variables; in this case, there are 10 element measurements constituting the variables and hence 10 components. When the original set of variables is clo- sely correlated, it is possible to derive a smaller number of underlying components to represent the original dataset while retaining most of the information in it. A score is assigned to each observation with respect to each principal component; this allows the identification of patterns in the data across observational units. PCA analyses was performed on STATISTICA Software.

\section{Results}

In vitro plant regeneration and AQUA1:GFP localization

At the end of in vitro regeneration, the transformation processes showed an efficiency of 6-7 \% for the two 
constructs, similar to those observed previously in the transformation protocol of the same clone (Confalonieri et al. 2000). Ten transgenic lines were created with the AQUA1:HA construct (Fig. 1 S1), and 7 with the AQUA1:GFP construct (data not shown). The expression of aqual:ha in all transgenic plants was assayed by RTqPCR by comparing the endogenous expression of aqual $P$. alba orthologs. Transgenic in vitro plantlets showed an increase of aqual expression in comparison to the endogenous transcript of wt plants (data not shown). When over-expressed in transgenic in vitro plantlets, the fluorescent signal of the AQUA1:GFP was detected in guard cells in leaves; however, in roots of the same plants, the fluorescent signal was detected in the cytoplasm (Fig. 1). From the over-expressing aqual in vitro plants, two different transformed lines (line 16 and line 22) were chosen for molecular and physiological analyses. To esti- mate the levels of aqual up-regulation in the acclimated transgenic plants, the qRT-PCR analyses were performed on fully expanded leaves of in vivo plants. Aqual gene was over expressed in leaves of transgenic line 16 and line 22 (?69 and ?5 FC, respectively) under $1 \mathrm{lM}$ and $1 \mathrm{mM} \mathrm{Zn}$ treatments (Fig. 2).

Fig. 1 Confocal imaging of AQUA1:GFP in transgenic over-expressing $P$. alba plants. a root, white field; b root, $488 \mathrm{~nm}$; c leaf, white field;

(d) leaf, $488 \mathrm{~nm}$. Bar represent $20 \mathrm{~lm}$
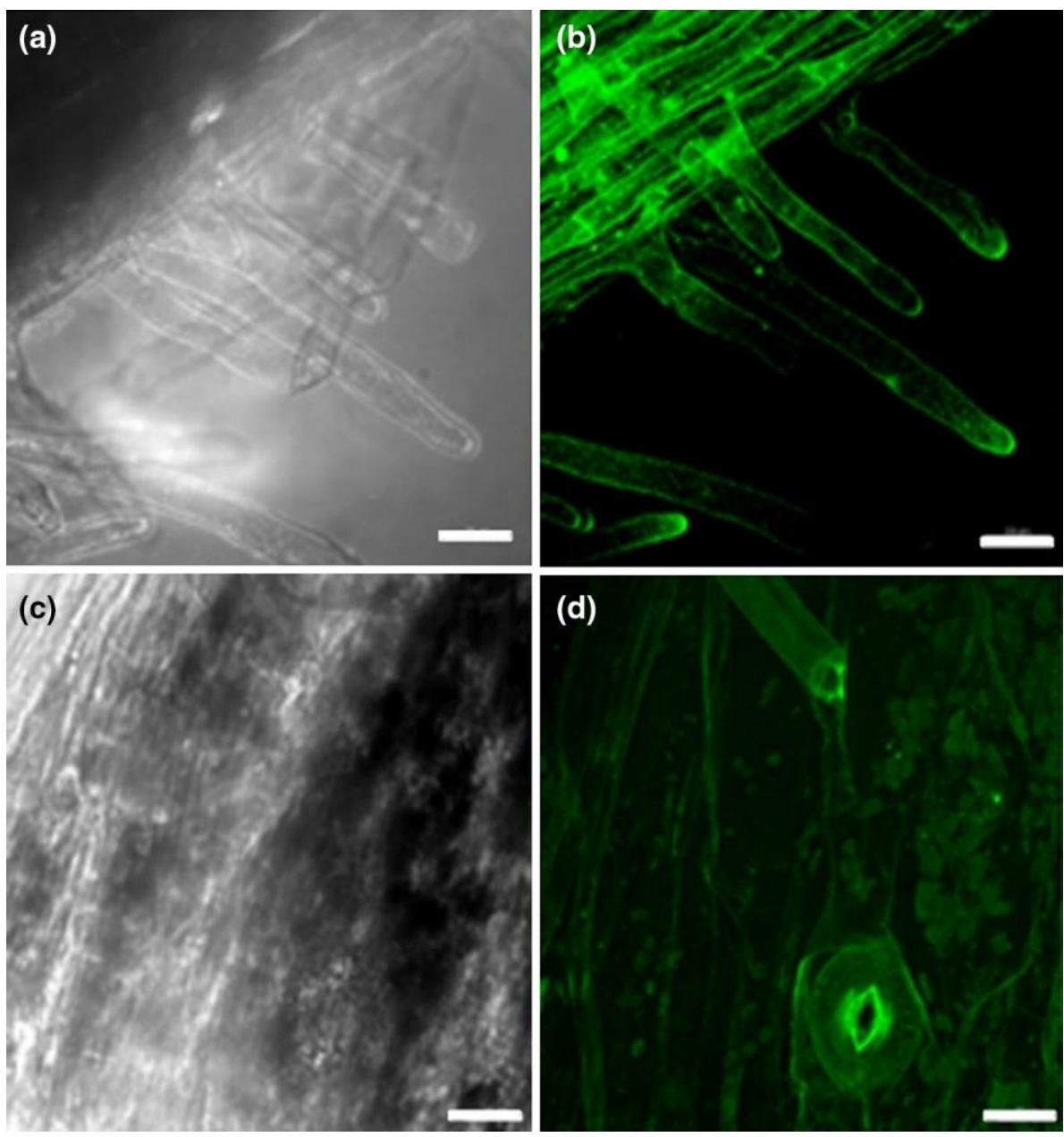

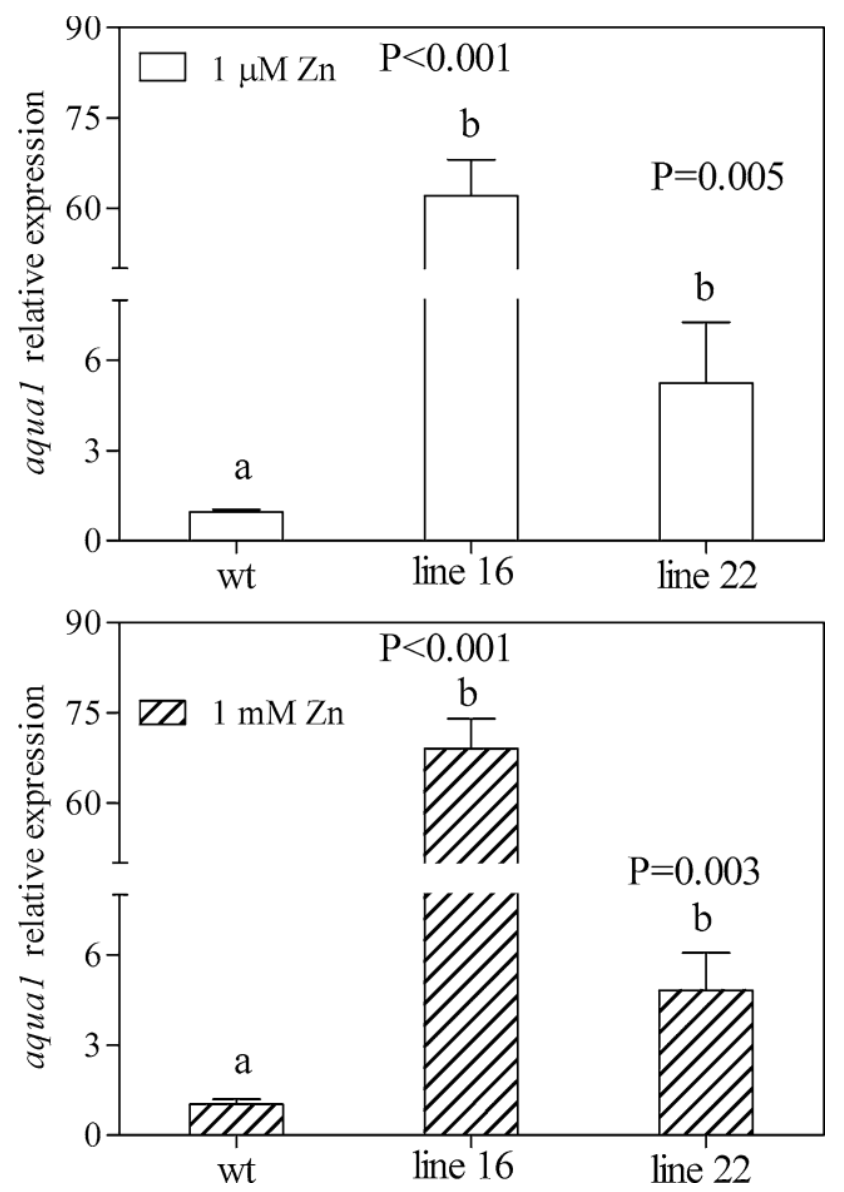

Fig. 2 Relative expression of aqual transcripts in leaves of trans-genic plants (lines 16 and 22) compared to in vivo wt plants under $1 \mathrm{lM}$ and $1 \mathrm{mM} \mathrm{Zn}$ treatments. Each histogram is the average of three independent biological samples with three technical replicates for each; error bars represent SD. $t$ test analyses was performed on data of transgenic plants $v s$ wt plants and letters denote differences among them

Concerning the fluorescence of Chl $a$, the maximum quantum yield of PSII (Fv/Fm) which gives the information about the proportion of the light absorbed by chlorophyll in PSII was reduced in apical leaves in all the lines exposed to Zn treatments (Fig. 7). 


\section{Comparison of growth parameters and $\mathrm{Zn}$ excess response among $P$. alba transgenic lines and wt plants}

Transgenic lines and wt plants, grown under the same conditions in the control chamber, were phenotypically indistinguishable. Although aqual gene expression levels in line 16 and line 22 were different compared to wt, no morphological differences were observed (Fig. 3).

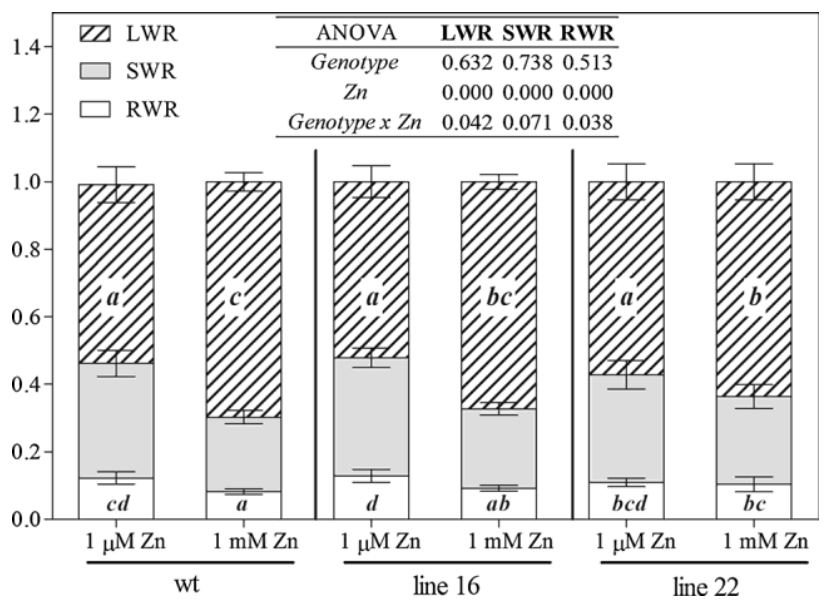

Fig. 3 Growth traits of Populus alba Villafranca clone in Control $(1 \mathrm{lM})$ and $\mathrm{Zn}$ treatments conditions (1 mM), calculated after 35 days of growth on wt, over-expressing line 16 and line 22. Leaf Weight Ratio (LMR), Stem Weight Ratio (SWR), Root Weight Ratio (RWR) results were analyzed by two-way analysis of variance (ANOVA) and means $(n=5)$ were subjected to Tukey Multiple Comparison Test at 0.05 probability level. Different letters indicate difference among organs and treatments

Also, the leaf maturation process, estimated from the changes in chlorophyll content (SPAD measurements) in growing leaves, was not different among lines and Zn treatments (Fig. S1). Moreover, relative water content did not show differences among lines and $\mathrm{Zn}$ treatments (Fig. S2).

Over-expression of aqual in transgenic Populus alba increases growth rate as compared to wt plants under optimal growth conditions (Fig. 4a). The significant dif- ferences $(P \backslash 0.05)$ of RGR between the transgenic lines and the wt plants were detected in leaves and at the whole plant level, but for other organs (i.e., roots and stem) line 22 showed an intermediate phenotype, without significant differences from both the wt and the line 16.

In particular, in leaves of both transgenic lines there was an increase of RGR of $* 25 \%$ as compared to wt plants, and at the whole plant level the increase is in the range of $21-26 \%$. 
(a)
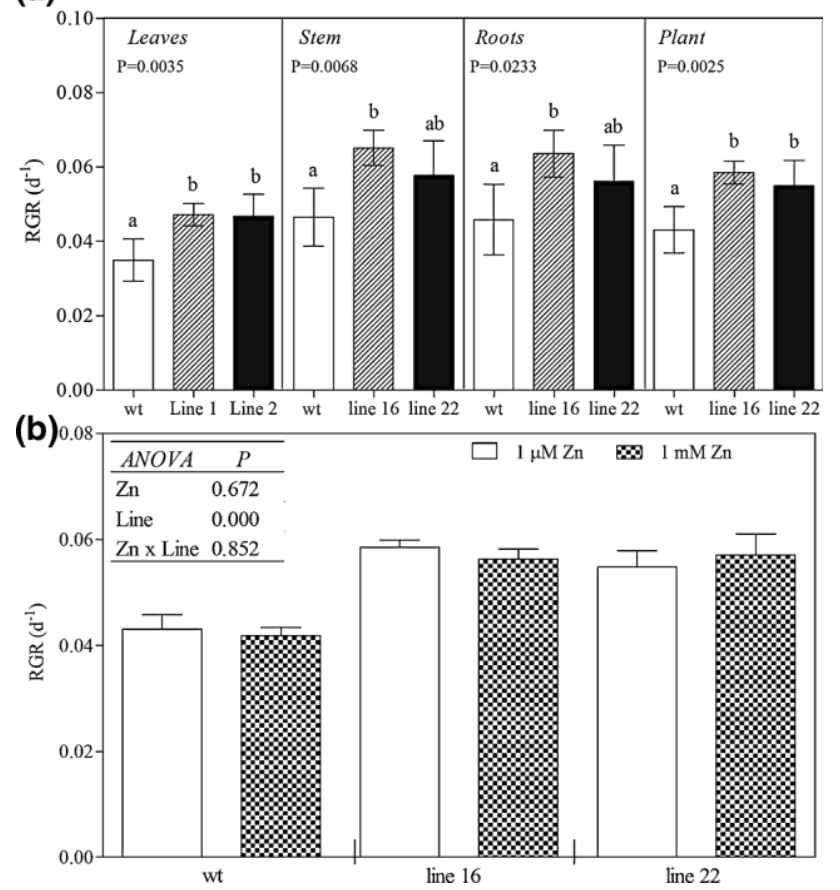

Fig. 4 Leaves, stem, roots, and wool plant relative growth rate (RGR) calculated after 35 days of $11 \mathrm{M} \mathrm{Zn}$ treatment on wt, line 16 and line 22 Populus alba Villafranca clone; results were analyzed by one-way analysis of variance (ANOVA) and means were subjected to Tukey multiple comparison test at 0.05 probability level (a). Comparison of RGR calculated on different lines after 35 days of $11 \mathrm{M}$ and 1 $\mathrm{mM} \mathrm{Zn} \mathrm{treatment;} \mathrm{results} \mathrm{were} \mathrm{analyzed} \mathrm{by} \mathrm{two-way} \mathrm{analysis} \mathrm{of} \mathrm{variance} \mathrm{(ANOVA).} \mathrm{Means}(n=5)$ were subjected to Tukey-Kramer multiple comparison test at 0.05 probability level (b)

For stem and roots, line 16 showed a significant increase of about $28 \%$ in both plants parts as compared to wt plants, instead line 22 showed an increase (not significant) of $* 15 \%$ for stem and $* 18 \%$ for roots. $1 \mathrm{mM}$ of Zn did not significantly affect plant RGR of either wt or transgenic plants (Fig. 4b). However, there was a significant effect $(P \backslash 0.001)$ of the line factor with a mean increase in both transgenic lines of plant RGR (Fig. 4a, b), regardless of the treatment condi- tion. The average increase of plant RGR in transgenic lines compared to wt, without considering the $\mathrm{Zn}$ treatments, was $* 26$ $\%$ for line 16 and $* 24 \%$ for line 22 . The over- expression of aqual determines a slight increase of $\mathrm{Zn}$ con- centration in leaves and roots in both transgenic lines. In particular, line 22 showed the higher $\mathrm{Zn}$ concentration (?17 \% in leaves and $? 15 \%$ in roots in comparison to wt plants). However, these differences in response to excess $\mathrm{Zn}$ were not significant when compared to wt plants (Fig. 5a), suggesting that AQUA1 was probably not involved in Zn- transport. Significant differences in Tolerance Index (Ti) were found in roots of transgenic plants (Fig. 5b). Ti was signifi- cantly higher in line 22, with an increase of $* 40 \%$ compared to wt plants. On the other hand, line 16 showed an intermediate phenotype with an increase $* 10 \%$ that is not significantly different from both the wt and the other transgenic line. 
(a)

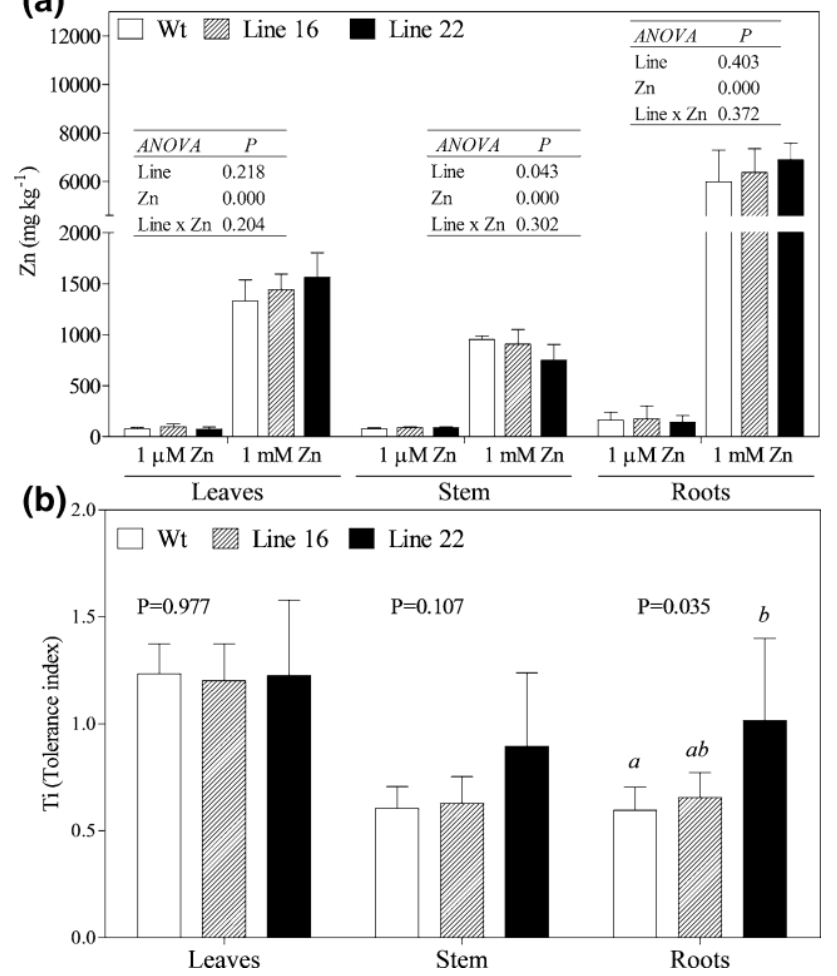

Fig. $5 \mathrm{Zn}$ concentration ( $\mathrm{mg} \mathrm{kg}^{-1}$ ) in leaves, stems, and roots of wt, over-expressing line 16 and line 22 of Populus alba Villafranca clone grown in hydroponic condition with $1 \mathrm{lM}$ and $1 \mathrm{mM}$ Zn for 35 days (a). Values are the means ? standard deviation $(n=5)$. Results were analyzed by two-way analysis of variance (ANOVA). Means were subjected to Tukey-Kramer multiple comparison test at 0.05 prob- ability level. Tolerance index calculated as ratio between the dry weight biomass of treatment ( $1 \mathrm{mM} \mathrm{Zn})$ and control (1 $1 \mathrm{M} \mathrm{Zn)} \mathrm{conditions} \mathrm{(b).} \mathrm{The}$ results were analyzed by one-way analysis of variance (ANOVA) and means were subjected to Tukey multiple comparison test at 0.05 probability level

\section{Gas exchange and photosynthetic parameters}

In order to understand the role of over-expression of aqual in transgenic Populus alba the photosynthetic parameters and chlorophyll $a$ analyses were performed at the end of 35 days of treatments. A loss in photosynthetic capacity in treated plants was observed only in wt line $(-67 \%)$ when analyzed at ambient $\mathrm{CO}_{2}$ (Table 1). The intrinsic Tran- spiration Efficiency calculated as ratio of net photosyn- thesis rate and $g_{\mathrm{s}}$ was significantly increased (2x) in transgenic $P$. alba line 16 and 22. Photosynthetic $\mathrm{CO}_{2}$ response curves $(\mathrm{A} / \mathrm{Ci})$ did not change between treatments on wt and line 22 showing an increase when $\mathrm{Ci}$ concen- tration overlaps $600 \mathrm{ppm}$ (Fig. 6). 

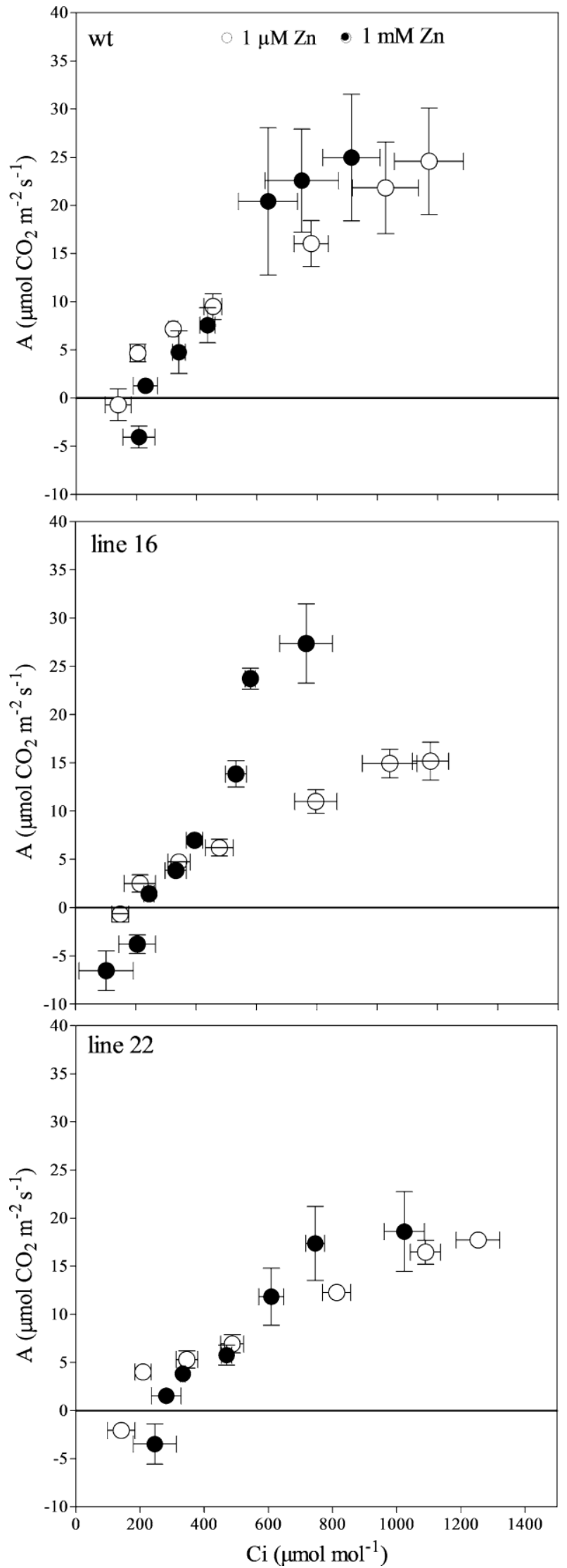

Fig. 6 Photosynthetic $\mathrm{CO}_{2}$ response curves $(\mathrm{A} / \mathrm{Ci}$ ) determined for the first fully expanded leaf on plants grown in $1 \mathrm{lM}$ and $1 \mathrm{mM} \mathrm{Zn}$ for 35 days. Each data are means of $n=3$ analyses. Abbreviations: $A \mathrm{CO}_{2}$ assimilation at saturating light level, $\mathrm{Ci}$ intercellular $\mathrm{CO}_{2}$ 

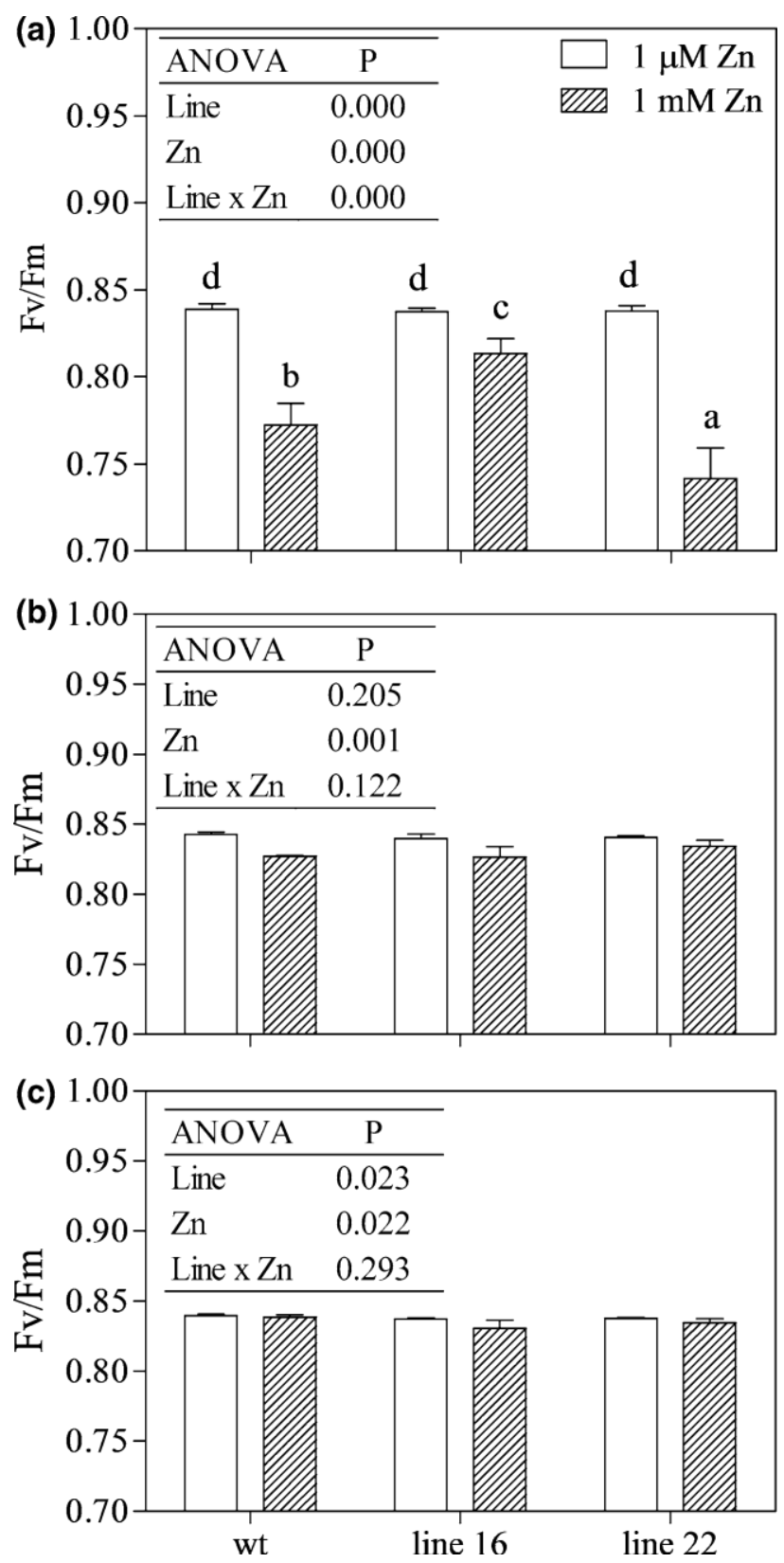

Fig. 7 Chlorophyll fluorescence parameter (Fv/Fm), analyzed on apical (a), median (b), and basal (c) leaves of Populus alba Villafranca clone grown in hydroponic condition with $1 \mathrm{lM}$ and $1 \mathrm{mM} \mathrm{Zn}$ treatments for 35 days. Values are means ? standard deviation $(n=5)$. Results were analyzed by two-way analysis of variance (ANOVA). Means were subjected to Fisher's LSD test at 0.05 probability level. Different letters represent significant differ- ences among treatments and line interaction 


\section{Element distributions in plants in relation to $\mathrm{Zn}$ uptake}

The PCA results indicate that mineral nutrients have a distinct response pattern in leaves, stem, and root tissues but the response pattern is similar in wt and transgenic lines. PCA conducted on nutrients data produced two sig- nificant PCs that, together, explain $86.5 \%$ of the total variance in the data and are retained for further analysis. The other nine components will not be discussed further because their eigenvalues are less than one and they con- sequently explain little of the variability in the dataset. $\mathrm{B}, \mathrm{Ca}$, and $\mathrm{N}$ show a similar distribution pattern to $\mathrm{S}, \mathrm{Mg}$, and $\mathrm{K}$ (Fig. 8). Each element has a high loading value on the first principal component (which explains $52.28 \%$ of the total variance). P, $\mathrm{Fe}, \mathrm{Mn}$, and $\mathrm{Cu}$ are positively associated with the second component (34.28\% of the variance) (Fig. 8 and Table S1). Once the association between the 10 elements and the two components is identified, the scores assigned to individual lines with respect to each component are analyzed in order to identify common patterns. A scatterplot of the scores of different line samples in a Fact.1/Fact.2 score space and are presented in Fig. 9. The scores are marked by their line names and related organs to identify possible differences in elements distribution between lines and organs. In the PCA scatterplot is possible to see a different organ and treatments distribution of the data, while no differences were detected between lines.

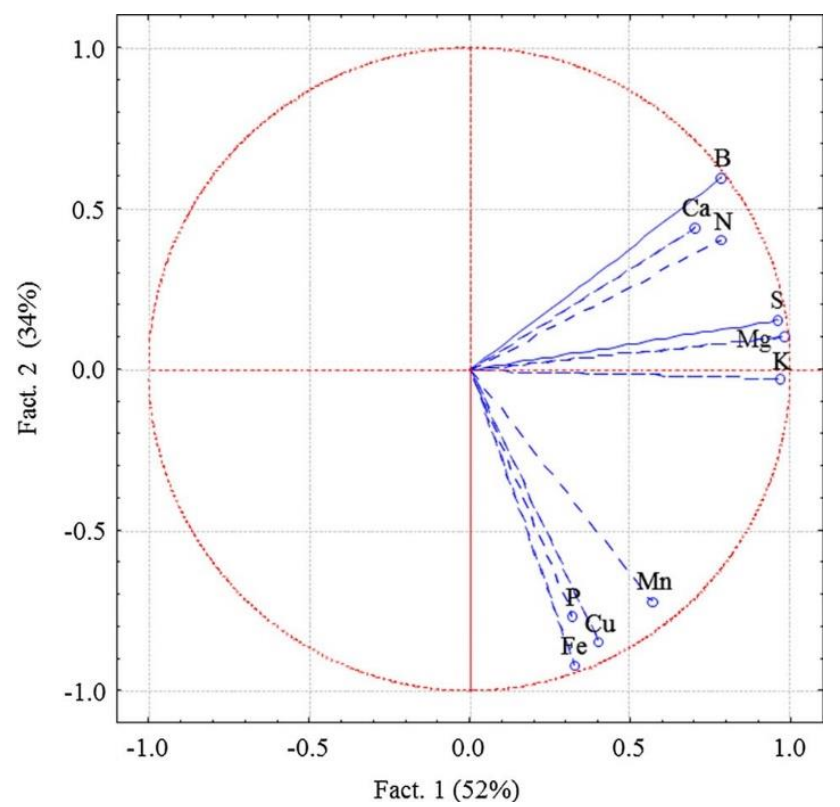

Fig. 8 PCA scores for different elements on lines (wt, line 22 and line 16) and organs (leaves, stem, and roots)

Fig. 9 PCA scores plot of nutrients data of Populus alba Villafranca clone grown in hydroponic condition with $1 \mathrm{lM}$ and $1 \mathrm{mM} \mathrm{Zn}$ treatments, indicating clustering of WT (wild type), line 16 (GM16) and line 22 (GM22) leaf, roots, and stem samples. The square represent treated clone, the circle identify control one. Different lines are reported in association with organs ( $R$ roots, $S$ stem, $L$ leaves)

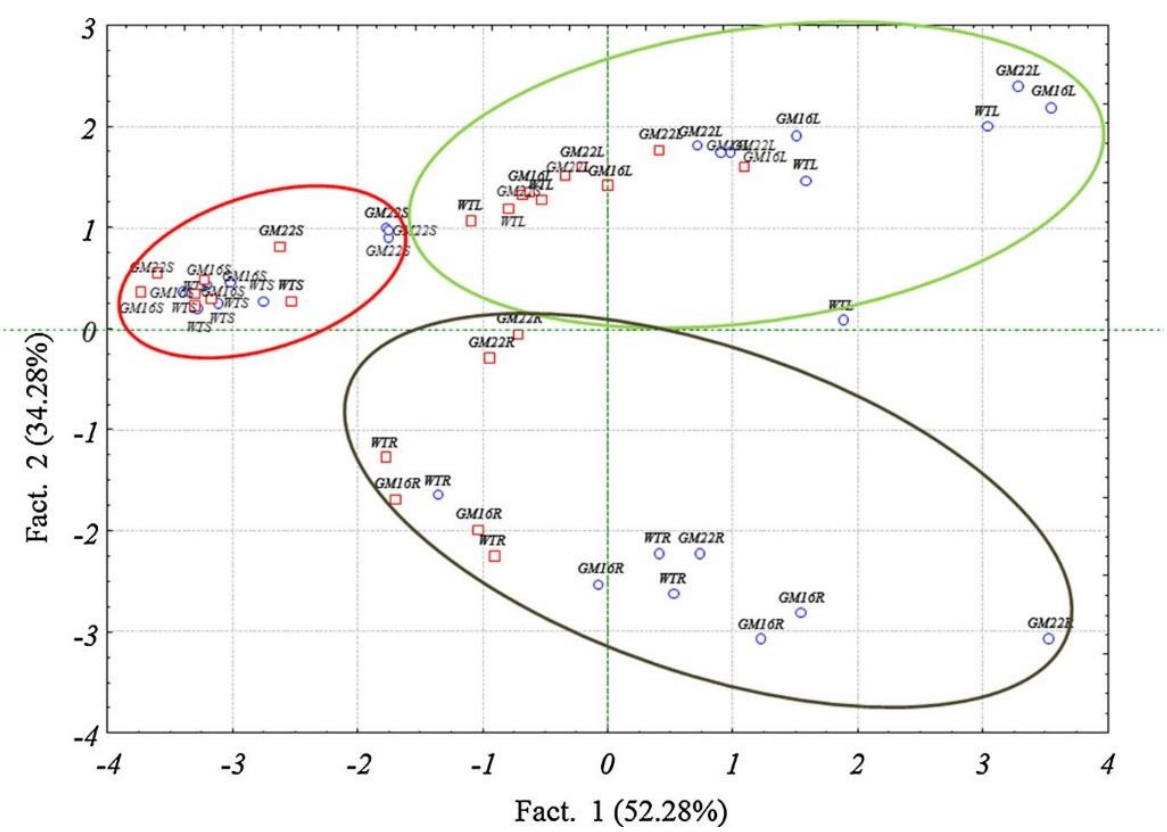


Table 1 Foliar gas exchange parameters estimated to ambient $\mathrm{CO}_{2}(395 \pm 20 \mathrm{ppm})$ in different lines of Populus alba Villafranca clone grown in hydroponic condition with $1 \mathrm{lM}$ and $1 \mathrm{mM} \mathrm{Zn}$ treatments

\begin{tabular}{|c|c|c|c|c|c|c|}
\hline & \multicolumn{3}{|l|}{ Line } & \multicolumn{3}{|c|}{ ANOVA } \\
\hline & wt & 16 & 22 & Line & $\mathrm{Zn}$ & Line $9 \mathrm{Zn}$ \\
\hline \multicolumn{7}{|l|}{ iTE } \\
\hline $1 \mathrm{lM} \mathrm{Zn}$ & $0.050 \pm 0.0023 a$ & $0.040 \pm 0.0099 \mathrm{a}$ & $0.035 \pm 0.0077 \mathrm{a}$ & 0.398 & 0.017 & 0.059 \\
\hline $1 \mathrm{mM} \mathrm{Zn}$ & $0.041 \pm 0.0112 \mathrm{a}$ & $0.080 \pm 0.0296 b$ & $0.071 \pm 0.0224 b$ & & & \\
\hline \multicolumn{7}{|l|}{$g_{\mathrm{s}}$} \\
\hline $1 \mathrm{lM} \mathrm{Zn}$ & $143 \pm 14.8$ & $120 \pm 3.6$ & $151 \pm 24.8$ & 0.757 & 0.000 & 0.157 \\
\hline $1 \mathrm{mM} \mathrm{Zn}$ & $63 \pm 21.1$ & $72 \pm 31.9$ & $57 \pm 13.8$ & & & \\
\hline \multicolumn{7}{|l|}{ A } \\
\hline $1 \mathrm{lM} \mathrm{Zn}$ & $7.2 \pm 0.95 c$ & $4.7 \pm 1.06 \mathrm{a}$ & $5.3 \pm 1.56 \mathrm{a}$ & 0.811 & 0.001 & 0.003 \\
\hline $1 \mathrm{mM} \mathrm{Zn}$ & $2.4 \pm 0.32 \mathrm{a}$ & $5.2 \pm 1.53 \mathrm{a}$ & $3.8 \pm 0.39 \mathrm{a}$ & & & \\
\hline
\end{tabular}

Values are mean \pm standard deviation $(n=5)$. Results were analyzed by two-way analysis of variance (ANOVA). Means were subjected to Fisher's LSD test at 0.05 probability level. Different letters represent significant differences among treatments and line interaction. Intrinsic Transpiration Efficiency (iTE) calculated as ratio of $\mathrm{A}$ and $g_{\mathrm{s}}$

$A \mathrm{CO}_{2}$ assimilation at saturating light level $\left(1 \mathrm{~mol} \mathrm{CO} \mathrm{Cm}^{-2} \mathrm{~s}^{-1}\right), g_{\mathrm{s}}$ stomatal conductance to water vapor (mmol $\mathrm{H}_{2} \mathrm{O} \mathrm{m} \mathrm{m}^{-2} \mathrm{~s}^{-1}$ 


\section{Discussion}

Plant aquaporins are involved in almost every aspect of plant life cycle such as cell growth and elongation, transpiration, seed germination, and response to biotic and abiotic stresses ( $\mathrm{Li}$ et al. 2013). Thanks to expression studies and the use of transgenic plants, the physiological roles of several aquaporins have been elucidated in the last few years. For instance, the expression of Arabidopsis AtTIP1;1 is induced by gibberellic acid (GA3), a phyto- hormone regulating cell growth, and its expression is strongly correlated with an increased cell size in different tissues (Ludevid et al. 1992; Philips and Huttly 1994). Moreover, over-expression in transgenic plants of Ara- bidopsis AtPIP1;2 and Panax ginseng PgTIP1 significantly increased plant growth rate when compared to wt plants (Aharon et al. 2003; Peng et al. 2007). Since the over- expression of aqual in transgenic Villafranca clones induced a general increase of plants growth rate (i.e., RGR), in comparison to wt plants, we suggest a major role of this aquaporin in regulation of plant growth and con- ferring better intrinsic transpiration efficiency.

The increased growth rate of transgenic plants over- expressing aquaporin genes has been related to increased mesophyll and stomatal conductance, resulting then in an increased $\mathrm{CO}_{2}$ assimilation and carbon fixation (Aharon et al. 2003). $\mathrm{CO}_{2}$ is assimilated through stomata that rapidly regulates their opening and closing by water movement between guard cells and the surrounding tissues (Roelfsema and Hedrich 2005). Specific guard cells localized aquaporins expression have been previously detected for several species such as Arabidopsis and N. tabacum (reviewed in Heinein et al. 2009). In sunflower, the expression of SunTIP7 transcripts were increased dur- ing stomatal closure (Sarda et al. 1997), suggesting the involvement of aquaporin in regulating guard cell water flux, and stomatal opening. In addition, some aquaporins showed also the ability to facilitate $\mathrm{CO}_{2}$ transport when expressed in Xenopus oocytes and in yeast cells (Heckwolf et al. 2011; Uehlein et al. 2003). Several studies, using overexpressing/silencing aquaporin mutants, showed also a positive correlation between the expression of these aquaporins and mesophyll conductance in different plant species, like rice, tobacco, and Arabidopsis (Heckwolf et al. 2011; Flexas et al. 2006; Hanba et al. 2004). The localization of aqual in guard cell in transgenic $P$. alba plants could suggest a possible involvement of this

aquaporin in regulation of stomatal gating. However, the over-expression of aqual did not significantly affect stomatal conductance in controlled conditions at simulated atmospheric $\mathrm{CO}_{2}$ and also did not affect fluorescence parameters. This could be explained by a possible buffering of aqual over-expression by post-translational regulation of its activity, and/or sub-cellular localization, in order to avoid an excessive transpiration. Indeed, in $V$. faba guard cell volume is regulated by kinase-dependent mechanisms involved in membrane trafficking (Shope and Mott 2006), such as phosphatidylinositol-3-kinase activity, that regulate also the sub-cellular localization of aqual in Arabidopsis protoplasts (Andreucci et al. 2015). Thus, it could be plausible that similar mechanisms could occur also in $P$. alba aqual overexpressing lines, resulting then in a sim- ilar stomatal conductance between transgenic and wt plants. On the other hand, it could be also possible that aqual could be involved mainly in cell growth and cell elongation, instead of regulating transpiration as also demonstrated by an increased RGR in transgenic lines.

In the past years, several aquaporins have been associ- ated with response to different environmental stresses ( $\mathrm{Li}$ et al. 2013; Maurel et al. 2008), probably through regula- tion of plant water status and transpiration. However, dif- ferent studies showed contrasting results of the role of aquaporin in response to stress, depending mainly on the plant species and the stress under investigation. Indeed, the over-expression of aquaporins in transgenic plants could confer both higher tolerance, or higher sensitivity to stresses, probably by modifying plant-water relations ( $\mathrm{Li}$ et al. 2013). Also heavy metal toxicity could affect water absorption and transport at the root (Prasad 1997; Barceló et al. 1986), but can also reduce leaf transpiration and water potential (Pandey and Sharma 2002). In addition, some aquaporins have been shown to directly transport heavy metals or to confer resistance to this stress when over- expressed in plants (Hove and Bhave 2011; Negishi et al. 2012; Zhang et al. 2008). Since aqual is down-regulated in response to Zn excess in $P . x$ euramericana I-214 leaves and roots (Di Baccio et al. 2011), we investigated the effect of its over-expression in response to excess $\mathrm{Zn}$ in $P$. alba over-expressing lines.

When exposed to $\mathrm{Zn}$ excess, the transgenic lines did not show any significant increase in $\mathrm{Zn}$ accumulation in roots and leaves, even though there was a slight increase in comparison to wt plants. Mineral elements analyzed by PCA, on the contrary, showed that $\mathrm{Zn}$ induces a reduction on other elements uptake but also in this case not related to factor line. In particular, the different responses of leaves and root analyzed reveal a distinct associations between PC1 and the mineral nutrients scores developed from PCA analysis. These results could be explained by the different physiological role of these organs. Since the over-expression of genes involved in heavy metal transport/homeostasis usually drastically increase metal accumulation in transgenic over-expressing plants (Sinclair and Krämer 2012; Adams et al. 2011), these results could suggest that aqual is not directly involved in Zn transport and homeostasis, but mainly in plant 
growth. The down-regulation of aqual in response to excess $\mathrm{Zn}$, showed by Di Baccio et al. (2011), is probably a mecha- nism for reducing plant growth in response to $\mathrm{Zn}$ stress, in order to avoid excessive accumulation of this metal.

Our results suggest that a general increase in water transport was detected in Populus alba transgenic plants. The Villafranca transgenic plants showed an increased tolerance, expressed as biomass production in excess $\mathrm{Zn}$ and control condition, toward excess $\mathrm{Zn}$ in roots. Anyway, the Villafranca clone did not show significant differences in $\mathrm{Zn}$ accumulation and partitioning between wt and transgenic plants. These results could suggest that aqual did not transport $\mathrm{Zn}$ and that the tolerance in roots tissues could be related to the increased growth rate shown by transgenic plants compared to wt.

Author contribution statement Andrea Ariani has contributed to the planning of the experiment, data col- lection and elaboration (transformation, gene expression), manuscript draft, and its final approval. Alessandra Fran- cini has contributed to the planning of the experiment, data collection and elaboration ( $\mathrm{Zn}$ concentration, chlorophyll fluorescence analyses, gas exchange measurement), manuscript draft, and its final approval. Andrea Andreucci has contributed to the planning of the experiment, data collection and elaboration (gene expression, confocal imaging collection), manuscript draft, and its final approval. Luca Sebastiani has contributed to the planning of the experiment, data collection and elaboration (Zn concentration, gene expression, statistical elaboration) of data manuscript draft, and its final approval.

Compliance with ethical standards

Conflict of interest The authors declare that they have no conflict of interest.

\section{References}

Adams JP, Adeli A, Hsu CY, Harkess RL, Page GP, dePamphilis CW, Schultz EB, Yuceer C (2011) Poplar maintains zinc homeostasis with a heavy metal genes HMA4 and PCS1. J Exp Bot 62:3737-3752

Agree P, Saboori AM, Asimos A, Smith BL (1987) Purification and partial characterization of te Mt 30,000 integral membrane protein associated with the erythrocyte Rh(D) antigen. J Biol Chem 262:17497-17503

Aharon R, Shahak S, Wininger S, Bendov R, Kapulnik Y, Galili G (2003) Overexpression of a plasma membrane aquaporin in transgenic tobacco improves plant vigour under favourable growth conditions but not under drought or salt stress. Plant Cell 15:439-447

Andreucci A, Ariani A, Sebastiani L (2015) In vitro functional characterization of AQUA1: a new poplar (Populus $x$ euramer- icana clone I214) aquaporin involved in Zinc stress. Interna- tional Plant Science Conferences (IPSC) from nature to Technological Exploitations. Florence 2-5 September 2014. Abstract p xviii

Ariani A, Gepts P (2015) Genome-wide identification and character- ization of aquaporin gene family in common bean (Phaseolus vulgaris L.). Mol Genet Genomics. doi:10.1007/s00438-015-1038-2

Arnon DI, Hoagland DR (1940) Crop production in artificial culture solutions and in soils with special reference to factors influenc- ing yields and absorption of inorganic nutrients. Soil Sci 50:463-485

Bae EK, Lee H, Lee JS, Noh EW (2011) Drought, salt and wounding stress induce the expression of the plasma membrane intrinsic protein 1 gene in poplar (Populus alba 9 P. tremula var. glandulosa). Gene 483:43-48

Barceló J, Poschenrieder C, Andreu I, Gunse B (1986) Cadmium-

induced decrease of water stress resistance in bush bean plants (Phaseolus vulgaris L. cv. Contender) I. Effects of Cd on water potential, relative water content and cell wall elasticity. J Plant Physiol 125:17-25

Besse M, Knipfer T, Miller AJ, Verdeil J-L, Jahn TP et al (2011) Developmental pattern of aquaporin expression in barley (Hordeum vulgare L.) leaves. J Exp Bot 62:4127-4142

Brunner AM, Yakovlev IA, Strauss SH (2004) Validating internal controls for quantitative plant gene expression studies. BMC Plant Biol 4:14. doi:10.1186/1471-2229-4-14

Chaumont F, Barrieu F, Wojcik E, Chrispeels MJ, Jung R (2001) Aquaporins constitute a large and highly divergent protein family in maize. Plant Physiol 125:1206-1215

Cohen D, Bogeat-Triboulot MB, Vialet-Chabrand S, Merret R, Courty PE, Moretti S, Bizet F, Guilliot A, Hummel I (2013) Developmental and environmental regulation of aquaporin gene expression across Populus species: divergence or redundancy? PLoS One 8:e55506

Confalonieri M, Belenghi B, Balestrazzi A, Negri S, Facciotto G, Schenone G, Delledonne M (2000) Transformation of elite white poplar (Populus alba L.) cv. 'Villafranca' and evaluation of herbicide resistance. Plant Cell Rep 19:978-982

Cui XH, Hao FS, Chen H, Chen J, Wang XC (2008) Expression of the Vicia faba VfPIP1 gene in Arabidopsis thaliana plants improves their drought resistance. J Plant Res 121:207-214

Di Baccio D, Tognetti R, Minnoci A, Sebastiani L (2009) Responses of the Populus 9 euramericana clone I-214 to excess zinc:car- bon assimilation, structural modifications, metal distribution and cellular localization. Environ Exp Bot 67:153-163

Di Baccio D, Galla G, Bracci T, Andreucci A, Barcaccia G, Tognetti R, Sebastiani L (2011) Transcriptome analyses of Populus 9 euramericana clone I-214 leaves exposed to excess zinc. Tree Physiol 31:1293-1308

Dickmann DI (1972) Photosynthesis and respiration by developing leaves of cottonwood (Populus deltoids Bartr.). Bot Gaz 132:253-259

Du J, Miura E, Robischon M, Martinez C, Groover A (2011) The Populus class II HD ZIP transcription factor POPCORONA affects cell differentiation during secondary growth on woody stems. PLoS One 6:e17458

Flexas J, Ribas-Carbó M, Hanson DT, Bota J, Otto B, Cifre J, McDowell N, Medrano H, Kaldenh R (2006) Tobacco aquaporin NtAQP1 is involved in mesophyll conductance to $\mathrm{CO}_{2}$ in vivo. Plant J 48:427-439 
Francini A, Nali C, Picchi V, Lorenzini G (2007) Metabolic changes in white clover clones exposed to ozone. Env Exp Bot 60:11-19

Gupt AB, Sankararamakrishnan R (2009) Genome wide analysis of major intrinsic proteins in the tree plant Populus trichocarpa: characterization of XIP subfamily of aquaporins from evolu- tionary perspective. BMC Plant Biol 9:134

Hacke UG, Plavcova L, Almeida-Rodriguez A, King-Jones S, Zhou WC et al (2010) Influence of nitrogen fertilization on xylem traits and aquaporin expression in stems of hybrid poplar. Tree Physiol 30:1016-1025

Hanba YT, Shibasaka M, Hayashi Y, Hayakawa T, Kasamo K, Terashima I, Katsuhara M (2004) Overexpression of the barley aquaporin HvPIP2;1 increase internal $\mathrm{CO}_{2}$ conductance and $\mathrm{CO}_{2}$ assimilation in the leaves of transgenic rice plants. Plant Cell Physiol 45:521-529

Heckwolf M, Pate DT, Keldenhoff R (2011) The Arabidopsis thaliana aquaporin AtPIP1;2 is a physiological relevant $\mathrm{CO}_{2}$ transport facilitator. Plant J 67:795-804

Heinein RB, Ye Q, Chaumont F (2009) Role of aquaporins in leaf physiology. J Exp Bot 60:2971-2985

Hove RM, Bhave M (2011) Plant aquaporins with non-aqua functions: deciphering the signature sequences. Plant Mol Biol 75:413-430 Hunt R (1978) Plant growth analysis. Camelot Press Ltd, Southampton Kjeldahl J (1883) Neue methode zur bestimmung des stickstoffs in organischen körpern (New method for the determination of nitrogen in organic substances). $Z$ Anal Chem 22(1):366-383

Kohler A, Delaruelle C, Martin D, Encelot N, Martin F (2003) The poplar root transcriptome: analysis of 7000 expressed sequence tags. FEBS Lett 542:37-41

Lee SH, Chung GC, Jang JY, Ahn SJ, Zwiazek JJ (2012) Overex- pression of PIP2;5 aquaporin alleviates effects of low root temperature on cell hydraulic conductivity and growth in Arabidopsis. Plant Physiol 159:479-488

Li GW, Zhang MH, Cai WM, Sun WN, Su WA (2008) Character- ization of OsPIP2;7, a water channel protein in rice. Plant Cell Physiol 49(12):1851-1858. doi:10.1093/pcp/pcn 166

Li G, Santoni V, Maurel C (2013) Plant aquaporins: roles in plant physiology. Biochim Biophys Acta. doi:10.1016/j.bbagen.2013. 11.004

Lloyd G, McCown B (1981) Commercially-feasible micropropaga- tion of Mountain laurel, Kolmia latifolia, by use of shoot tip culture. Inter Plant Propagat Soc 30:421-427

Lopez D, Bronner G, Brunel N, Auguin D, Bourgerie S et al (2012) Insights into Populus XIP aquaporins: evolutionary expansion, protein functionality, and environmental regulation. J Exp Bot 63:2217-2230

Ludevid D, Höfte H, Himelblau E, Chrispeels MJ (1992) The expression pattern of the tonoplastic intrinsic protein c-TIP in Arabidopsis thaliana is correlated with cell enlargement. Plant Physiol 100:1633-1639

Marjanovic Z, Uehlein N, Kaldenhoff R, Zwiazek JJ, Weiss M et al (2005) Aquaporins in poplar: what a difference a symbiont makes! Planta 222:258-268

Matsumoto T, Hian HL, Su WA, Tanaka D, Liu C, Iwasaki I, Kitagawa Y (2009) Role of the aquaporin PIP1 subfamily in the chilling tolerance of rice. Plant Cell Physiol 50:216-229

Maurel C (1997) Aquaporins and water permeability of plant membranes. Annu Rev Plant Physiol Plant Mol Biol 48:399-429

Maurel C, Verdoucq L, Luu DT, Santoni V (2008) Plant aquaporins: membrane channels with multiple integrated functions. Ann Rev Plant Biol 59:595-624

Nakagawa T, Nakamura S, Tanaka K, Kawamukai M, Suzuki T, Nakamura K, Kimura T, Ishiguro S (2008) Development of R4 gateway binary vectors (R4pGWB) enabling high-throughput promoter swapping for plant research. Biosci Biotechnol Biochem 72:624-629

Negishi T, Oshima K, Hattori M, Kanai M, Mano S, Nishimura M, Yoshida K (2012) Tonoplast- and plasma membrane-localized aquaporinfamily transporters in blue hydrangea sepals of aluminum hyperaccumulating plant. PLoS One 7:e43189

Pandey N, Sharma CP (2002) Effect of heavy metals $\mathrm{Co}^{2 ?}, \mathrm{Ni}^{2 ?}$ and $\mathrm{Cd}^{2 ?}$ on growth and metabolism of cabbage. Plant Sci 163:753-758

Peng Y, Lin W, Cai W, Arora R (2007) Over-expression of a Panax ginseng tonoplast aquaporin alters salt tolerance, drought tolerance and cold acclimation ability in transgenic Arabidopsis plants. Planta 226:729-740

Perrone I, Gambino G, Chitarra W, Vitali M, Pagliarini C et al (2012) The grapevine root-specific aquaporin VvPIP2;4N control root hydraulic conductance and leaf gas exchange under well-watered conditions but not under water stress. Plant Physiol 160:956-977 Philips AL, Huttly AK (1994) Cloning of two gibberellin-regulated cDNAs from Arabidopsis thaliana by subtractive hybridization: expression of the tonoplast water channel, c-TIP, is increased by GA3. Plant Mol Biol 24:603-615

Postaire O, Tornaire-Roux C, Grondin A, Boursiac Y, Morillon R, Schäffner AR, Maurel C (2010) A PIP1 aquaporin contributes to hydrostatic pressure-induced water transport in both the root and rosette of Arabidopsis. Plant Physionl 152:1418-1430

Prasad MNV (1997) Trace metals. In: Prasad MNV (ed) Plant ecophysiology. New York, USA, pp 207-249

Quigley F, Rosenberg JM, Shachar-Hill Y, Bohnert HJ (2001) From genome to function: the Arabidopsis aquaporins. Genome Biol 3:1-17

Robinschon M, Du J, Miura E, Groover A (2011) The Populus class II HD ZIP, popREVOLUTA, influence cambium initiation and patterning of woody stems. Plant Physiol 155:1214-1225

Rodgers-Melnick E, Mane SP, Dharmawardhana P, Slavov GT, Crasta OR et al (2012) Contrasting patterns of evolution following whole genome versus tandem duplication events in Populus. Genom Res 22:95-105

Roelfsema MRG, Hedrich R (2005) In the light of stomatal opening: new insight into 'the Watergate'. New Phytol 167:665-691

Romeo S, Francini A, Ariani A, Sebastiani L (2014a) Phytoremedi- ation of Zn: identify the diverging resistance, uptake and biomass production behaviours of poplar clones under high zinc stress. Water Air Soil Pollut. doi:10.1007/s11270-013-1813-9

Romeo S, Trupiano D, Ariani A, Renzone G, Scippa GS, Scaloni A, Sebastiani L (2014b) Proteomic analysis of Populus 9 euramer- icana (clone I-214) roots to identify key factors involved in zinc stress response. J Plant Physiol 171:1054-1063

Romeo S, Lombardi L, Andreucci A, Lux A, Stephen Horner D, Sebastiani L (2015) RNA sequencing of Populus $x$ canadensis roots identifies key molecular mechanisms underlying physio- logical adaption to excess zinc. PloS One. doi:10.1371/journal. pone.0117571

Sade N, Vinocur BJ, Diber A, Shatil A, Ronen G, Rissan H, Wallach R, Karchi H, Moshelion M (2009) Improving plant stress tolerance and yield production: is the tonoplast aquaporin SITIP2;2 a key to isohydric to anisohydric conversion? New Phytol 181:651-661

Sakurai J, Ishikawa F, Yamaguchi T, Uemure M, Maeshima M (2005) Identification of 33 rice aquaporin genes and analysis of their expression and function. Plant Cell Physiol 26:1568-1577

Sarda X, Tousch D, Ferrare K, Legrand E, Dupuis JM, Casse-Delbart F, Lamaze T (1997) Two TIP-like genes encoding aquaporins are expressed in sunflower guard cells. The Plant J 12:1103-1111

Secchi F, Zwieniecki MA (2010) Patterns of PIP gene expression in Populus trichocarpa during recovery from xylem embolism suggest a major role for the PIP1 aquaporin subfamily as moderators

of refilling process. Plant Cell Environ 33:1285-1297

Shope JC, Mott KA (2006) Membrane trafficking and osmotically induced volume changes in guard cells. J Exp Bot 57:4123-4413 
Sinclair SA, Krämer U (2012) The zinc homeostasis network of land plantRoes. Biochim Biophys Acta 1823:1553-1567

Song J, Lu S, Chen ZZ, Lourenco R, Chiang VL (2006) Genetic transformation of Populus trichocarpa genotype Nisqually-1: a functional genomic tool for woody plants. Plant Cell Physiol 47:1582-1589

Su X, Chu Y, Li H, Hou Y, Zhang B et al (2011) Expression of multiple resistance genes enhances tolerance to environmental stressors in transgenic poplar (Populus x euramericana 'Guar- iento'). PLoS One 6:e24614

Tuskan GA, Difazio S, Jansson S, Bohlmann J, Grigoriev I et al (2006) The genome of black cottonwood, Populus trichocarpa (Torr. \& Gray). Science 313:1596-1604

Uehlein N, Lovisolo C, Siefritz F, Kaldenhoff R (2003) The tobacco aquaporin ntAQP1 is a membrane $\mathrm{CO}_{2}$ pore with physiological functions. Nature 425:734-737

Wilkins DA (1957) A technique for the measurement of lead tolerance in plants. Nature 180:37-38

Wullschleger SD, Weston DJ, DiFazio SP, Tuskan GA (2012) Revisiting the sequencing of the first tree genome: populus trichocarpa. Tree Physiol 33:357-364

Zhang Y, Ma K, Sadana P, Chowdhury F, Gaillard S, Wang F, McDonnell DP, Unterman TG, Elam MB, Park EA (2006) Estrogen related receptors stimulate pyruvate dehydrogenase kinase isoform 4 (PDK4) gene expression. J Biol Chem 281(52):39897-39906

Zhang Y, Wang Z, Chai T, Wen Z, Zhang H (2008) Indian mustard aquaporin improves drought and heavy-metal resistance in tobacco. Mol Biotechnol 40:280-292 